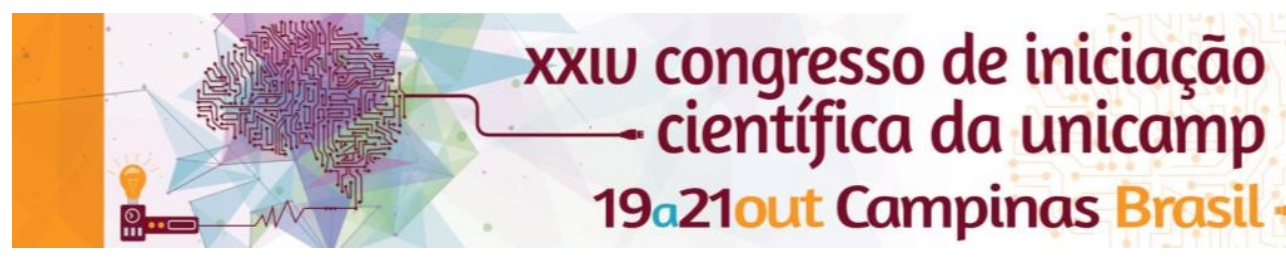

\title{
Desemprego e suicídios no Brasil: uma análise empírica
}

\author{
Juliana Petta do Nascimento*, Marcelo Justus.
}

\section{Resumo}

Do ponto de vista econômico, alguns fatores são relevantes quando se tratam das mortes por suicídios, sendo que os principais deles são o efeito negativo sobre o capital humano e alto custo para o Estado. Foram abordados vários estudos sobre o tema, tal como a relação de variáveis econômicas e sociais nos atos de suicídio, expressas desde muito tempo nos manuscritos de Karl Marx e Émile Durkheim, sendo também estudada a "Teoria Econômica do Suicídio" de Hamermesh e Soss. Além disso, foi criado um banco de dados composto pelos estados brasileiros de 1980 a 2011, período marcando por grandes mudanças na economia brasileira, contendo além da taxa de suicídios, diversas variáveis econômicas, sociais e demográficas, a fim de criar um modelo econométrico que trouxesse os dados para o caso brasileiro.

Palavras-chave:

Suicídios, Brasil, Desemprego.

\section{Introdução}

Este trabalho tem por objetivo a análise empírica de como o desemprego pode influenciar na taxa de suicídio do Brasil nas ultimas décadas, levando em consideração os aspectos principais do problema.

O suicídio é um ato no qual um indivíduo elimina a sua vida. De acordo com a OMS (2000), a morte por suicídio é um problema de saúde pública, pois vem aumentando a cada dia e gera um alto custo ao Estado, além da perda de capital humano.

Essa discussão é antiga na Economia e na Sociologia tendo aparecido nos manuscritos Marx (2006) e Durkheim (1977). Para Durkheim, o suicídio é um fato social, fazendo com que seu estudo parta do exterior para atingir o interior, ou seja, é criada uma taxa natural de suicídios que significa uma aptidão definida para o mesmo. Marx, por outro lado, parte da análise da vida privada, com o objetivo de fazer uma crítica social, dado que para ele, o suicídio se tratava de uma sociedade doente que deveria ser modificada social e economicamente.

Somente com a teoria econômica do suicídio de Hamermesh e Soss (1974), publicada no Journal of Political Economy, que as causas do suicídio passaram a ser empiricamente investigadas pelos economistas. Eles tinham por objetivo explicar o porquê o suicídio tinha tendência de aumentar com a idade.

\section{Resultados e Discussão}

Através da análise do banco de dados podemos perceber que o suicídio no Brasil vem crescendo desde 1980, tendo uma leve queda entre 1999 e 2000 (gráfico 1).

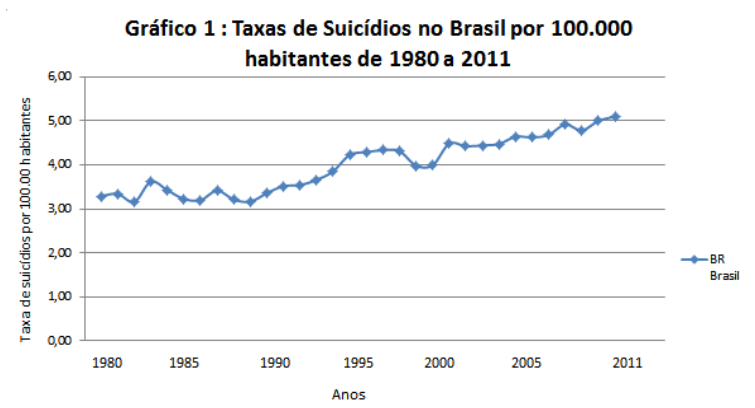

Em relação ao gênero (gráfico 2), o sexo masculino em todos os anos possui maiores taxas de suicídio do que as mulheres. Apesar dos jovens terem menores taxas de suicídio comparadas com as do sexo masculino, eles possuem taxas mais elevadas do que das mulheres.

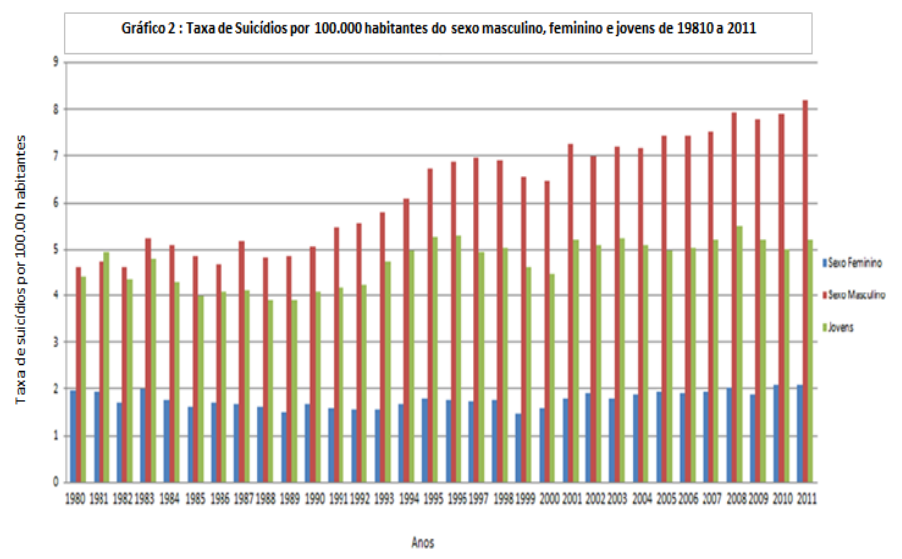

\section{Conclusões}

Tanto os dados quanto a literatura estudada mostram que as taxas de suicídios no Brasil crescem a cada ano. Além disso, pouca importância é dada pelos economistas brasileiros sobre o tema.

Então, concluímos ser muito importante entender sobre o suicídio no Brasil, a fim de enriquecer a pesquisa sobre o tema no país.

Durkheim, E. (1977). O Suicídio: estudo de sociologia [1897] (trad. Luz Cary, Margarida Garrido e J.Vasconcelos Esteves). Lisboa: Editorial Presença/Martins Fontes.

Hamermesh, D. S. and N. M. Soss (1974). An economic theory of suicide. The journal of political economy, 83-98.

Marx, K. (2006). Sobre o suicídio. Boitempo Editorial

OMS (2000). Prevenção do suicídio: um manual para médicos clínicos gerais. Technical report, Organização Mundial da Saúde, Genebra. 